\title{
How to Nail the Multiple Identities of an Organization? A Content Analysis of Projected Identity
}

\author{
Robert Heckert $^{1}{ }^{(D} \cdot$ Jelle Boumans $^{1} \cdot$ Rens Vliegenthart $^{1}$
}

Published online: 3 September 2019

(C) The Author(s) 2019

\begin{abstract}
Multiple-identity organizations possess identity characteristics that belong to different and potentially conflicting value systems. How exactly these identities are projected in such an organization's external communication has hardly been investigated. Here, we present a method that provides a systematic way to analyse the projected identity of multiple-identity organizations. A quantitative content analysis of the annual reports of a Dutch multiple-identity organization shows the presence of its utilitarian and ideological identity through the years 1998-2016. Results suggest that the relatively strong emphasis on the ideological identity of the organization is not in line with the identity perceived internally. Contextual knowledge about changes in the leadership, stakeholders' demands, and the annual turnover provides a more thorough understanding of the research results. This study shows the volatility of identity, and it supports the presupposition that multiple-identity organizations are flexible in adapting their identity to changing circumstances.
\end{abstract}

Keywords Multiple identity · Projected identity · Content analysis · Identity change

\section{Introduction}

Is it Dr Jekyll or Mr Hyde we are dealing with today? Multiple identities are rather intangible, and so much goes for organizational multiple identities. The identity of an

Robert Heckert

Robert.heckert@gmail.com

1 University of Amsterdam, Maxwellstraat 24, 1097 EW Amsterdam, The Netherlands organization is reflected in the answer of organizational members to the question what the core characteristics of the organization are. In a multi-identity organization, this answer is multi-vocal. Multiple-identity organizations harbour qualities of both an ideological as well as a utilitarian identity (Pratt and Foreman 2000). The underlying value systems do not see eye to eye with each other. The normative or ideological system (emphasizing traditions and traditional symbols, internalization of an ideology, and altruism) is like that of a church or family and the utilitarian system (characterized by economic rationality, maximization of profits, and self-interest) like that of a business (Albert and Whetten 1985; Foreman and Whetten 2002: 621).

Multi-identity organizations could be misunderstood, more so than single-identity organizations, sending ambiguous messages to their audiences. In this time and age, a sound corporate identity is paramount for the success of a commercial company. Also, public and semi-public organizations not only face specific demands in keeping the public's trust (Bryce 2007). They are subject to the same immutable laws of marketing as profit-centred companies are (Ries and Trout 1993). They must involve in the fight of perceptions of their stakeholders and deal with transparency, just like for profit companies (Kotler 1979). They are often dependent on subsidies, governmental approval of their plans for the future, access to the potential labourforce and for long-term support by their stakeholders (Arnett et al. 2003). This is common practise for organizations like universities, hospitals, housing, and broadcasting corporations. It demands a relevant, unique, distinguishing market-proposition and a clear and solid image.

Academic literature on multiple-identity organizations is scarce (Ramarajan 2014), especially when it concerns the 
external communication of those identities. In this study, we try to unravel how multiple identities are projected externally. Since the prominence of the subsequent identities are subject to change over time (Bayle-Cordier et al. 2015; Heckert 2019), the study applies a longitudinal design. The way of communication and the emphasis that is placed on one identity over another, can give an idea of the organization's priorities (Andersson et al. 2003: 235) and about its desired image. Studying this in a longitudinal way helps to expose the dynamic nature of identity formation and communication.

Previous studies on the organizational identities have taken a qualitative approach, revealing the recurring typologies of multiple identities (Albert and Whetten 1985; Foreman and Whetten 2002), the importance of understanding underlying values (Desai 2017), the organizational triggers of ambivalence (Ashforth et al. 2014), the manipulability of identities (Sillince and Brown 2009), and the intractable character of a multi-identity (Glynn 2000; Fiol et al. 2009). This study adds to the existing knowledge in two ways: first, it offers a quantitative framework for the analysis of the projected identity of multiple-identity organizations, and second, it shows how projected identity changes over time can be made tangible. The quantitative approach in this study provides an objective and systematic way to measure ideological and utilitarian identity. The goal is to provide a systematic measure for the prevalence of identities in organizational communication.

The approach will be applied in a quantitative content analysis of the annual reports of the multi-identity organization Sanquin, the Dutch Blood Supply Foundation. While Sanquin operates as a not-for-profit semi-public organization, a number of market-oriented business units are part of the same foundation. By analysing annual reports, covering a period of almost two decades, the presence of the two identities will be examined over time. Specifically, the study aims to answer the following research question: How are the multiple identities of Sanquin projected externally over time? Annual reports are ideal for this purpose since they are official communications of the organization itself, targeted at a wide variety of stakeholders. They are available for multiple consecutive years, enabling the researcher to study developments in the prevalence of the identities over a large period of time (Van Riel 2012).

To understand the organizational identity dynamics, contextual conditions need to be considered, like stakeholders' changing demands, economic ups and downs, and internal turbulence like leadership changes.

\section{Theory}

\section{Identity}

An organization's identity is the organization's answer to the question 'Who are we?'. Specific identity traits must express the organizational core in centrality, distinctiveness, and enduringness. So, organizational identities are the features of an organization that organizational members perceive as ostensibly central, distinctive, and enduring in character and contribute to how they define the organization and their identification with an organization (Jäger and Schröer 2014; Van Riel 2012). In a previous study, we concluded that the enduring characteristic is disputable and that dynamic continuity offers a more realistic account (Heckert 2019). This means that identity is rather continuous than enduring. 'Enduring' is a static notion, while 'continuous' implies that changes within a certain bandwidth are possible, and even likely. The organization redefines itself during its existence, responsive to external and internal changes. Some organizational traits live through the years, others do not.

\section{Projected Identity}

The projected identity refers to the image communicated by the organization. It is 'the corporate image embodied in visual icons, corporate logos, tag lines, and message points. It also refers to the desired image that the dominant coalition in the organization projects through mission and vision statements, credos, speeches, and expressions of organizational identity and core values' (Carroll 2008: 3466). It is generally accepted that the projected identity sprouts from the organizational identity, as a self-presentation of the organization through communications. Identity will lead the projection rather than vice versa (Davies and Chun 2002: 144), although the organization's portrayal, especially internal, for its part also influences the organizational culture and the identity in the long term (Schultz et al. 2000). Constructs like corporate image, identity, projected image, and reputation are often superimposed or confused, as Cian and Cervai state in their effort to propose a standard terminology and bring all definitions 'under the reputation umbrella' (Cian and Cervai 2014: 182). The organizational projected image is how the organization would like to be perceived by its customers (Cian and Cervai 2014: 184). Organizations also convey, through communication, aspirational values (Cian and Cervai 2014: 191). The latter is an important consideration for this study, because the essence of the tension in a multi-identity can be found in seemingly incompatible value-based identity traits of the organization. Accordingly, the first research question is: 
RQ1. To what extent are the ideological and the utilitarian identity projected in the communicated content?

\section{Multiple Identities}

The answer to the identity question is far from univocal for multiple-identity organizations (Albert and Whetten 1985). Multiple views on the identity traits are not necessarily antithetical, nor do they need to be universally held by all organizational members. Those members even do not have to be conscious of the distinct views. The multiple identities can be retained by specific subgroups that exist in different parts of the organization. This is commonly referred to as an ideographic multiple identity (Pratt and Foreman 2000).

Many authors use the terms multiple identity and hybrid identity interchangeably (Battilana and Lee 2014: 400-401). Here, we deliberately use 'multiple' instead of 'hybrid'. The concept of 'hybrid identity' differs from the concept of 'multiple or dual organizational identity' as the latter considers the different identities independently next to each other. Hybrids systematically integrate both identities (Jäger and Schröer 2014: 1285). The case study analysed in this paper is a multiple-identity organization with a legally grounded and internally recognized separation between private (market) and public (non-market) activities. Publicness is defined as a characteristic of an organization which reflects the extent to which the organization is influenced by political authority. The wide range of organizations now providing healthcare services are not easily classified as either public or private. (Anderson 2012: 320-321).

There is an interplay between sectoral affiliation and identity characteristics, but legal status is not the decisive factor for having either an ideological or a utilitarian identity. A private enterprise can have ideological traits. Nestlé, for instance, is selling sugar-based products, but it also develops preventive treatments and therapies for lifestyle diseases in foodstuffs in its Institute of Health Sciences, managed by health freaks. A public organization can have utilitarian characteristics, as for example a museum that sells merchandise articles. Multi-identities have characteristics from both identity domains.

The multi-identity character of an organization is not necessarily problematic. Tensions can arise, however, when the identity is composed of two or more types that would usually not be expected to go together and when the identity is constituted according to two seemingly incompatible value systems. Specifically, the literature has identified two contrasting value systems, the normative or ideological system (emphasizing traditions and traditional symbols, internalization of an ideology, and altruism) like that of a church or family; and a utilitarian system (characterized by economic rationality, maximization of profits, and self-interest) like that of a business (Albert and Whetten 1985; Foreman and Whetten 2002: 621). Organizations create and propagate myths that reconcile ideological inconsistencies, such as discrepancies between the values held by the organization and the policies adopted to enact them (Pratt and Foreman 2000: 33). Scholars usually focus on multiple-identity organizations where this tension of clashing values occurs, especially concerning the value systems of the ideological and the utilitarian identity.

The notions ideological (or normative) and utilitarian (or economic) are often used in academic literature about multiple identities (e.g. Albert and Whetten 1985; Glynn et al. 2000: 731), although not per se in these exact terms: the terminology is often context-dependent. In a case study on rural cooperatives, for instance, those cooperatives are described as 'normative-utilitarian hybrids', thus distinguishing a normative and a utilitarian identity (Foreman and Whetten 2002). Similarly, Pratt and Foreman (2000) present a case of a prototypic ideological or normative organization as an age-old monastic order that owns and operates a gourmet restaurant and convention centre on the grounds of its abbey, associated with a utilitarian identity. Pratt and Foreman use the same ideological and utilitarian wordings as Albert and Whetten (1985) and Glynn et al. (2000). Glynn (2000) investigated the 1996 musicians' strike at the Atlanta Symphony Orchestra. She mentions embedded and latent identity conflicts between the ideologies of musicians (artistic excellence) versus the staff's economic utility. Jäger and Schröer (2014) call it the tension between social and economic issues, when an organizational identity systematically integrates civil society and markets. Osborn and Ashforth (1990) have identified safety and profit-oriented identity characteristics at nuclear power plants that correspond with ideological and utilitarian traits. These examples show that context-specific comparable notions are used to describe the identities of a multiple-identity organization that are generally related to social and economic traits.

The ideological and utilitarian identities have distinct characteristics (Albert and Whetten 1985; Foreman and Whetten 2002; Jäger and Schröer 2014). The ideological organizational identity is associated with interest in the common case, the public interest, with public service corporations and a focus on social goals instead of financial gains. It is also called 'normative'. The utilitarian identity is associated with commercial goals, a business-like attitude and a private instead of a public governance. Our second research question is: 
RQ2a. How much attention is paid to both identities in terms of text volumes in (Sanquin's) annual reports?

Apart from volume, we will also assess possible differences in the presence of the identities between different types of text. A reference to an identity that is highlighted in a streamer, for instance, is more prominently visible than a reference to an identity that appears in the body of a text. We thus ask the sub-question:

RQ2b. Does the amount of attention paid to both identities differ between text types?

The answer to the sub-question could reveal the organization's preferences regarding the projected identity.

\section{Static or Dynamic?}

The enduring character of identity has, since the seminal and often iterated publication of Albert and Whetten (1985), hardly been discussed for two decades. Nowadays, it is not only common management lingo to say that change is the only tradition worth preserving (e.g. O'Brien 2017); also, academics recognize the anthropomorphic character of organizations (King 2015; Tuškej and Podnar 2018; Ashforth et al. 2018). Organizational identity is shifting from 'what' to 'who' (Ashforth et al. 2018). The implication of the attribution of human qualities to a non-human entity is that we assume organizations to shape their identities as human beings do: they preserve some identity anchors, but other identity traits are disposed of and replaced by new ones. If an organization is seen as a personality, the isolated analysis of identity characteristics alone will not have sufficient explanatory power. The context when conceptualizing and studying personality is of utmost importance (Kashdan and McKnight 2011).

The environment of most organizations is beset by continuous change, instability, flux, and unpredictability. If organizations are to survive and prosper under such conditions, they must be capable of dynamic adaption and stable and reliable performance (Ansell et al. 2015). Institutions can master the challenge of being responsive and stable at the same time. The validity of the comparison between individuals and organizations is not totally unquestioned, because much theorizing has been based on deductions metaphorically transferred from just theorizing about human identities, rather than being based on empirical observations. A number of explanations based on these deductions can be criticized as theoretically naïve and empirically false (Cornelissen and Harris 2001). This study tries to find a theoretically as well as empirically legitimate way to gain insights into the corporate multiple identity and its dynamics.
Other scholars support the dynamic character of identity via another paradigm. They acknowledge the reciprocal interrelationships between identity and image and argue that organizational identity, rather than enduring, is better viewed as a relatively fluid and unstable concept (Gioia et al. 2000). Identity is seen as an asset that should be managed (Pratt and Foreman 2000). Somewhere on the continuum between continuity and change the identities are, for instance, managed discursively in narrative texts of organizational identity (Chreim 2005).

From the insight of anthropomorphic organizations and their flexible identity, it is only a small step to argue that it might be easier for multiple-identity organizations to adapt their identity to changing circumstances. After all, they already incorporate ideological as well as utilitarian identity characteristics. The mere emphasizing of one set of traits and values at the cost of the other could be a sufficient adaptation to changing circumstances. Insights into identity change are relevant because this type of change is probably the organizational change with the most potential for disruption (Corley and Gioia 2004).

This leads to our third research question:

RQ3: How does the prominence of the various aspects of the organization's identity, more specific the prominence of the utilitarian and the ideological identity, reflected in the communicated content (the projected identities), evolve over time?

\section{The Manifestation of Identities in Annual Reports}

Annual reports are suitable communications to analyse identity projection (Van Riel 2012: 32). They provide a substantial amount of data and potentially show identity developments over time. The reports can be considered an annual thermometer of the organization's projected identity. Annual reports not only 'give feedback on goals and resources in accordance with the plan and budget' (Andersson et al. 2003: 236), but are usually presented as an annual 'state of the union'. They are a central 'communication device' (Breton 2009: 191) and annual reports are also public information officially stating intentions on future policies (Andersson et al. 2003: 238). As such, the content of annual reports is more often analysed to reveal an organization's priorities (for instance, about health promotion within local authorities; Andersson et al. 2003: 235). Haniffa and Hudaib (2007), for example, explored the ethical identity of Islamic Banks via communication in annual reports, and they explain this choice as follows. They chose corporate annual reports rather than other media of communication in assessing communicated ethical identity because these reports offer a snapshot of management's mindset in a particular period, have greater 
potential to influence due to widespread distribution, are more accessible for research purposes, and are used by a number of stakeholders as the sole source of certain corporate information (Haniffa and Hudaib 2007: 99). Jones, who investigated the dissemination of customer satisfaction results in the corporate annual report, claims that 'the annual report is the primary document used by public companies to communicate with shareholders and other interested parties including the media, investment community, and employees' (Jones 2006: 60). Annual reports are increasingly meant to establish the organization's corporate identity (Lee 1994: 215). Even more than other corporate communications, the annual report 'is designed to convey the positive message of the firm' (Breton 2009: 189). It 'employs language biased towards the positive' (Rutherford 2005: 349). An organization tends to project its desired identity. This identity does not necessarily correspond with the identity as perceived within the organization (Van Riel 2012:29).

\section{Research Method}

To investigate how the identity is projected, we conduct a quantitative content analysis. It builds on a previous multiple-identity study in which the case was used of a multiple-identity organization, the Dutch blood supply foundation Sanquin (Heckert 2019).

The multiple-identity character of the organization was first characterized on a theoretical basis, identifying organizational traits provided in academic literature (e.g. Foreman and Whetten 2002) for both the ideological and the utilitarian identity. In-depth interviews with organizational members were used to refine the universal indicators for the identities and to add case-specific identity traits. The obtained insights were used to identify a set of issues and questions for semi-structured interviews and a quantitative survey. This led to the conclusion that Sanquin is a multiple-identity organization, since organizational members give different answers to the identity question (Who are we?). On top of that there is the inherent and legally grounded hybrid nature of the organization that could make the casus a most likely case and a representation of other multiple-identity organizations (Eisenhardt and Graebner 2007). For the current study, the communicated content of this organization is analysed.

\section{Sample and Units of Analysis}

To investigate the prevalence of multiple identities, a sample of annual reports is analysed. The census sample consists of all annual reports, covering the entire existence of the organization, from 1998 to 2016. During this period between 1998 and 2016, the composition of the report has been changed several times. It may or may not contain a social report, a scientific report, and a financial report. Subject for analysis is the common denominator: the general body text of the corporate report, without appendices. The report of the Supervisory Board, a chapter in the annual report, is left aside, because of its low contentdensity, procedural character and given the semi-external position of the Board. Every report contains an introduction by the chairman of the executive board. This introduction is the not-for-profit equivalent of the letter to the shareholders.

The units of data collection are the respective annual reports. The registration unit can be either a paragraph, a short, isolated text section, a highlighted 'streamer' or quote, or a visualized text section. For most analyses, the paragraphs have been aggregated to the chapter level. A chapter in an annual report is, for instance, an interview, or a report of one of the organizational departments.

\section{Ideological and Utilitarian Identity Constructs}

A codebook including two sets of indicators was constructed; one set captures the ideological and one the utilitarian dimension. Below and in Table 1, we describe the indicators of both identities. All indicators are dichotomous; they can be either present or absent in the registration unit.

The entire process consisted of the following six steps. The first three steps have served as a basis for this study and have been described more elaborately elsewhere (Heckert 2019). First, a multiple-identity organization was characterized on a theoretical basis: the identities were boiled down to the ideological and the utilitarian identity. Academic literature provided us with indicators for both identities. Second, qualitative in-depth interviews with members of a multiple-identity organization were used to refine the universal indicators for the identities in an iterative process and to add case-specific identity traits. These traits were the orientation on human needs (focus on the donors' well-being) and on the importance of processes of the utilitarian identity (attention for the pharmaceutical industry). Besides the ideological and utilitarian traits, the employees recognized overarching characteristics (Dutch, healthcare, and blood), binding the organization together (Pratt and Foreman 2000: 20).

Third, the obtained insights are used to identify a set of issues and questions for semi-structured interviews (see "Appendix A") and on top of that propositions are formulated to be scored by employees. This makes the qualitative data more tangible. 
Table 1 Means and factor solutions

\begin{tabular}{lll}
\hline Does the registration unit refer to...? & $\begin{array}{l}\text { Mean references per } \\
\text { registration unit } N=339\end{array}$ & $\begin{array}{l}\text { Ideological } \\
\text { identity }\end{array}$ \\
\hline Process centred & 1.9 & $\begin{array}{l}\text { Utilitarian } \\
\text { identity }\end{array}$ \\
Social & .65 & .83 \\
Healthcare & .61 & .74 \\
Human centred & .46 & .49 \\
Business-like & .36 & .61 \\
Patient's health & .26 & .63 \\
Customer centred & .23 & \\
Central position of donor & .23 & \\
Self-reflection, utilitarian & .23 & \\
Self-reflection, ideological & .17 & \\
Patient as a consumer of medicines & .17 & \\
Donor as a producer of raw material & .09 & .75 \\
Commercial & .08 & \\
Altruism & .02 & \\
\hline
\end{tabular}

This table shows the main variables used in the Codebook (column 1) and their prevalence (column 2). Columns 3 and 4 show the factor solutions used for scale construction, by principal axis factoring: Varimax rotation with Kaiser normalization, aggregated values, only factor loadings $>.40$ are presented (Stevens 1992)

The fourth step is taken in this study and is meant to capture the projected identities in organizational communications by a content analysis. Fifth is to compare the identity perceived internally with the projected identity. The final step entails mapping out identity development over time; in this case to assess whether the internally observed fast shift towards a stronger utilitarian identity at the expense of ideological values is also present in the organization's communication.

\section{Ideological Identity}

Since blood for transfusion is donated by voluntary and non-remunerated donors in the Netherlands, altruism seems to be an asset that could also pervade the organization that is responsible for this blood collection. The focus of an ideological organization could be more on the well-being of human beings, in this case donors and patients, rather than on processes and on the needs of customers. The attitude is a social one, focused on human needs. The not-for-profit character and the public or semipublic background of an organization underline its ideological identity, because these traits are associated with the common good.

\section{Utilitarian Identity}

The utilitarian identity finds its basis in economic principles. The organization thinks and acts like a business. The goals are financial, and the mindset is commercial. To be successful attention must be paid to the demands of the customer. A utilitarian organization is supposed to be of private ownership. The importance of the human factor might be underestimated in favour of the attention for wellflowing processes. The implication of this underrating is that people, in this case donors as well as patients, are merely seen as production units and consumers. A strong focus on business partners (in this case the pharmaceutical industry) rather than donors and patients is also indicative of a utilitarian identity.

The coding team consisted of four communication science students of two universities. Before the actual content analysis took place, they have all thoroughly been trained by the principal investigators by means of a one-day instruction meeting at the premises of the case study organization. All coders coded about the same amount of texts.

We use Lotus to assess intercoder reliability. Lotus defines the proportion of agreement with a reference value, which is the most common coded value per coding unit (Fretwurst 2015). To determine the intercoder reliability, we used the standardized Lotus score (S-Lotus), which corrects for random agreements between coders. The intercoder reliability score of a random sample of material that is coded by all coders ( $n=55)$ is more than sufficient. Only one of twelve indicators scored a S-Lotus score $<.7$ ('is a reference made to public needs?'): S-Lotus .67), and the other variables scored between .75 and .98 (commercial). 


\section{Results}

\section{Prominence of Identity Traits}

We can observe that the same traits that were mentioned by the organizational members appear in the annual reports indeed, but some of the variables that were dominantly mentioned in the qualitative research (Heckert 2019), only play a subordinate part in the annual reports. On the one hand, altruism, for instance, was rather central in the interviews but was hardly present in the texts $(M=.02)$, and thereby excluded from the ideological construct. On the other hand, the process-oriented character was not mentioned often by the employees but turned out to be omnipresent in the annual reports. On average, a unit contains 1.9 references to processes (Table 1).

\section{Identity Constructs}

The first research question focuses on the presence of the ideological and the utilitarian identity in the communicated content. To determine this, first the scales of both identities are constructed. After an iterative process, the indicators that have a substantial presence are included in the final factor analysis (at least .25, see Table 1; the initial correlation matrix is entered in "Appendix B"). In addition, the indicator 'commercial' has been included because it is considered a defining characteristic of the utilitarian identity. Principle axis factoring analysis has been performed to assess whether the different traits indeed measure both identities. Orthogonal iterations of rotation (varimax) were used because we do not consider the two factors to be correlated. This is consistent with the theoretical notion of organizational multiple identity where identities are distinct if they are based on different value systems.

We do not expect a very strong correlation between the indicators of the respective identities, since this would mean that in every registration unit (for instance a paragraph) multiple subsequent indicators should occur, which is unlikely. This is particularly the case when quotes or streamers are the registration units, since these small units of text focus on single issues and can reasonably only contain a single indicator of identity. For this reason, the units of analysis taken into account for the factor analysis are the chapters and the short, isolated pieces of text $(n=339)$. The far-right column of Table 1 presents the factor loadings of the items.

The factor analysis enables us to recognize that the traits social, human centred, and patients' health mentioned form a coherent set of variables that we call the ideological identity. The organization's position in health care was recognized as a general property in the interviews, but the projection of this identity trait is connected with the ideological identity. The traits commercial, process oriented, and business-like form the second factor and represent the utilitarian identity.

The factor analysis (see Table 1) shows that there is a positive correlation between the two sets of items and the two components. The factors have an eigenvalue of 3.41 (ideological) and 2.03 (utilitarian). All factor loadings are $>.45$ and the squared loadings (total variance explained) are .45 (ideological) and .52 (utilitarian), which shows that valid scales have been construed (see "Appendix C" for a visualization in a scree plot).

The internal reliability of the scales is measured by the Cronbach's alpha coefficient of internal consistency. For the ideological identity, $\alpha=.65$. The alpha coefficient of the construct that reflects the utilitarian identity is $\alpha=.56$. Deleting the item 'business-like' would slightly improve the reliability, but with respect to the richness of the construct we decided to maintain all three items. While the internal reliability scores do not meet the common formal standard $(>.7)$, in this specific case of content analysis where associations between indicators is expected to be less strong, as outlined above, we consider this result as satisfactory. While usually scale analysis is used in survey analysis and items that measure the same concept are expected to correlate highly, in content analyses with multiple specific items for a single construct this is less evident: multiple items can capture the same underlying concept, but written texts are likely to only focus on just one, or a few, of those items. In that sense, the alpha scores indicate a considerable overall correlation between the items that belong to the same identity. Both constructs will be used for further analysis by computing the mean score of the maintained items per registration unit. For the ideological identity $M=1.53, S D=2.29$, and for the utilitarian identity $M=.49$. $S D=1.23$, a substantial difference.

Regarding our first research question, we can conclude that the ideological identity can validly and reliably be recognized in the communicated content. The indicators that are expected to represent the utilitarian identity form a construct as well, but this construct has a relatively low internal reliability. While this implies that the results must be treated with caution, the two constructs will be used to analyse and discuss the multiple-identity question. For the remainder of the analyses, we treat the constructs as dichotomous: the identities are either present or absent in a registration unit.

\section{Presence of Identities}

Our second research question deals with the amount of attention paid to both identities in terms of text volumes. 
Sub-question is whether there is an association between identity and text type.

Overall in $74.5 \%$ of the units an identity characteristic could be coded. In those texts, the ideological identity was more often present than the utilitarian identity. The utilitarian identity is present in $18.3 \%$ of the texts, the ideological in $56.2 \%(n=342$, see Table 2$)$. The identities are not equally divided over text types. We can split up the units into three distinctive types: quotes or streamers, short texts, and articles. When texts are emphasized by using a streamer or a quote, or when short texts are used, the utilitarian identity is almost absent. This identity is relatively more present in the body text (article), as can be seen in Table 2.

The presence of the ideological identity is almost equal for all text types. This is reflected by a very low Goodman and Kruskal's tau $(\tau=.003)$, indicating that the text type cannot predict the presence of the ideological identity. The predictability of the utilitarian identity suffers from the small amount of observations. For the utilitarian identity, Goodman and Kruskal's tau $(\tau=.11)$ is very weak as well, which means that we can hardly predict the utilitarian identity by text type neither.

Answering research question 2, we can conclude that there is a noticeable difference in volume between the two identities. The ideological identity (two-third) more than doubles the utilitarian identity (quarter) in the projected identity. This discrepancy is consistent across different types of text.

\section{The Projected Identities Over Time}

The third research question concerns the prominence of the identities over time. How do they evolve?

The previous study (Heckert 2019) mentioned the unanimously reported change of the quantitative relationship between the identities, during a period of a few years (2013-2016). In the eyes of the organizational members, the utilitarian identity was emerging fast, at the expense of the ideological identity. Is this internally experienced change projected in the organization's external communication? Is in this projection the utilitarian identity 'eating' the ideological identity, as felt by the employees? Figure 1 shows the prominence of both identities between 1998 and 2016.

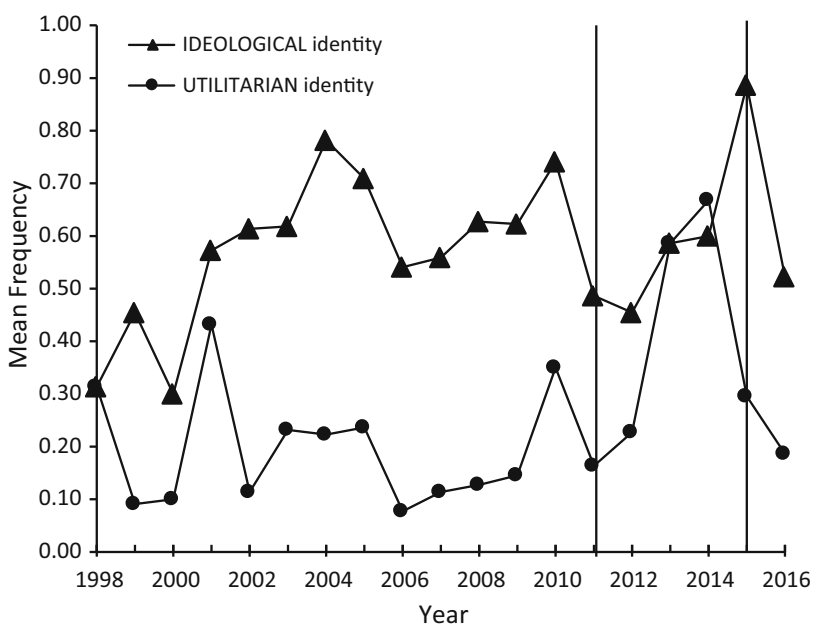

Fig. 1 The projected identities over time; the leadership: 1: the engineer (1998-2011). 2: the entrepreneur (2011-2015). 3: the diplomate (2015-2016). The qualifications (see "Appendix D") are given by the author who worked for a decade close to the presidents of the board. The interim president of 2014, the caretaker, who consciously refrained from leaving his mark on the organization, has been left out of consideration

From Fig. 1, we can infer that for the entire period 1998-2016, there is no robust trend of projected identity change. Although the $F$-test indicates that publication year has a statistically significant, positive influence on the presence of both identities [utilitarian: $F(1,337)=22.95$, $p<.001$ and ideological: $F(1,337)=37.90, p<.001]$, the effect size is relatively small (utilitarian: $R^{2}=.06$, ideological: $R^{2}=.10$ ). We can conclude that annual reports have become both more ideological and utilitarian identityfocused during the years. Noticeable is that the development in the prominence of both identities roughly follows the same lines.

Figure 1 shows clearly that during the entire period, except for 2014, the ideological identity is projected more heavily than the utilitarian identity. The ideological identity is present in three out of four identity-containing units, and the utilitarian identity in one out of four identitycontaining units.

Both identities have three peaks with a grand finale in the years 2013-2015. The distance between the identities grows between 2001 and 2013, and there is stronger identity profiling in one period compared to the other. Overall the 'identity saturation' slightly increases during

Table 2 Mean presence of identities per text type in percentages $(n)$

\begin{tabular}{lllll}
\hline & Quote or streamer $(n=120)$ & Short text $(n=119)$ & Article $(n=220)$ & Total $(n=459)$ \\
\hline Utilitarian identity & $4.2(n=5)$ & $8.4(n=10)$ & $31.4(n=69)$ & $18.3(n=84)$ \\
Ideological identity & $51.7(n=62)$ & $58.8(n=70)$ & $57.3(n=126)$ & $56.2(n=258)$ \\
\hline
\end{tabular}


the years observed, especially in the years 1998-2010 and 2012-2015.

The answer to the third research question is nuanced. The identities are evolving over time indeed, but the development is rather capricious. Both slightly incline, the ideological identity more than the utilitarian. For the long run, the ideological identity is two or three times more prominent than the utilitarian identity. The projected identity does not mirror the direction of the identity change towards economic utilitarianism perceived internally.

\section{Explaining Sanquin's Communicated Identity}

While the content analysis of the annual reports provides a valuable insight in the prominence of the identities, it does not explain patterns and variance. In this section, a number of contextual factors will be discussed that can potentially account for the patterns in the prominence of the identities over time. This hermeneutic approach is built on the first author's decade-long professional experience in the organization and on his observations. To add a holistic understanding of the context on the singular interpretation of the texts by content analysis (Bhattacherjee 2012: 116), we try to develop a more comprehensive understanding of the identity dynamics.

The financial performance of the organization is one such context. At the start of the merger-organization in 1998, the turnover of the public activities (the Blood Bank, reflecting the ideological identity) constituted about twothird of the organization's total, while the commercial activities cover the other third. In 2016, these proportions are reversed. On the basis of our content analysis, we must conclude that the projection of the identities does not keep pace with this development. There is no utilitarian identity cannibalizing the ideological identity in the projected communication.

In 2014, a drastic drop of turnover occurred, resulting in red figures for the one and only time in the organization's history. The legitimacy and even the existence of the organization were at stake. This may have been a reason to emphasize identity traits more than ever, as demonstrated in Fig. 1: an inclining 'identity saturation', foremost by the ideological identity.

The peaks of the ideological identity can also be explained in the context of stakeholder management. The increased prominence of the ideological identity in the years 2000-2010 could be explained by the organization's need to give prominence to a widely liked Blood Bank, underexposing the pharmaceutical activities. The view within the organization was that a non-commercial image would be more beneficial for donor recruitment as well as for the affability of the government.
This hide-and-seek game was amplified in the years 2012-2016 by the demands of the Minister of Health who urged a legal restructuring of the organization to safeguard the blood supply from possible commercial failure of the Pharma activities. The increased attention for the organization behind the blood supply (Veuger 2018) might explain the increased need to comfort the Ministry of Health and the Parliament with ideology-rich communication.

It is difficult to say if the leadership of the organization shapes the projected identity, or that the organization gets the leader it needs at a specific point in time. The CEO of a company is responsible for the annual report, and he or she is usually the one who writes the introduction. The tone at the top that CEO's set by example and action is central to the overall ethical environment of their firms (Schwartz et al. 2005). One might expect that the CEO's view is reflected in the report. Could there be a connection between the projected identity and the administration in charge at a certain time and age? Figure 1 shows that there indeed appears to be some correlation. The first period (1998-2011) shows, after the establishing years (1998-2000), an increase in prominence of the ideological identity and the utilitarian identity augmenting at a lower level. Once the first President of the Board leaves the organization, more variation in the identity can be observed. The utilitarian peak is recorded in the period in office of the entrepreneurial CEO, who left the organization after a few years in office. A new peak of the ideological identity is found after the arriving of his successor. Overall, there seems to be an irrefutable association between the character of the CEO (see description in "Appendix D") and the characteristics of the projected identity.

\section{Conclusions and Discussion}

Around the turn of the century, many public organizations have been privatized or made semi-public (Van Damme 2004; Cuadrado-Ballesteros and Peña-Miguel 2018). This brought an unexpected need for identity management. The identity of multi-identity organizations in particular turned out to be rather difficult to manage and hard to understand for external stakeholders (Zafar 2016). The acknowledgement and legitimacy of this kind of organizations was no longer self-evident. This might lead to overemphasizing the ideological identity, as demonstrated in our case.

In academic literature, the multiple-identity organization is a suppositious subject, and the phenomenon is hardly made tangible. This study offers a method to gain systematic insight into the multiple identity of this kind of organizations. It focusses on how a multiple-identity organization projects its identity by its communication. 
The results can be compared with the internally perceived identity. The development of the hybrid character of the organization over time is made visible, which was not documented before.

The research goals were to recognize the ideological and the utilitarian identity in communicated content; to assess whether this image matches the internally perceived identity; and to assess whether the identities change over time. The findings may not only deepen the insights into multiple identities but could provide a fruitful starting point for identity management as well.

Organizational identity can be empirically determined (Heckert 2019), and in the current study, a content analysis of the projected identity lays the projected identity open quantitatively. This enables the comparison between the actual identity and the projected identity. The projected identity does not, in this case, reflect the internally observed identity entirely. Some traits were omnipresent in the qualitative interviews but were hardly projected in the reports, like altruism. An explanation for this discrepancy in this example could be that the altruistic principle is a value the employees find important rather than that it is an organizational identity characteristic. This value was obviously felt important and put under pressure in the perception of the employees at the time of the empirical data-gathering.

A second finding worth emphasizing is that identity is indeed not as stable as often assumed (Albert and Whetten 1985). Organizational identity is dynamic, and its development resembles that of an individual person (King 2015). The internally perceived identity change in the period 2013-2016 in our case, from ideological to more and more utilitarian, is not projected in the reports. Overseeing shorter periods of time, some temporary trends are perceptible. Noticeable is that the 'identity saturation' of both identities follow the same lines. It seems like an 'antidote' has been given, consciously or unconsciously, when the two identities got 'out of sync'. Besides that, the characteristics of the CEO in office appear to influence the emphases in the communicated content.

The 'identity talk' in the annual reports and the emphasis on one identity or the other do not seem to be determined by the events and results of the year under review rather than by the need or want of bringing underexposed or agreeable characteristics into the limelight. This conclusion confirms that (projected) identity is manageable (Pratt and Foreman 2000) and that organizations try to convey, through communication, aspirational values (Cian and Cervai 2014: 191). For external observants, hidden principle is that for a not-for-profit organization the ideological identity is more suitable than the utilitarian identity is. Organizations obviously prefer to send positive messages (Rutherford 2005), especially in their annual reports (Breton 2009), and in the desired identity (Van Riel 2012), the ideological identity is more socially acceptable than the utilitarian identity.

If organizations tend to communicate their priorities in annual reports (Andersson et al. 2003), these priorities do not seem to be the strategical or economic focus points, but rather desired image-driven preferences. This might be typical for not-for-profit organizations. At least multiidentity non-profits can orchestrate their projected identity instantly and over time by focussing on the ideological identity and limiting utilitarian communication, or the other way around. This provides them with a more flexible identity management tool than single-identity enterprises. It enables multiple-identity organizations to play a subtle game with their identities and to realize relatively rapid change in projected organizational identity when needed. The implication of this conclusion is that mere statistical data do not suffice to understand the observed identity changes over time. Contextual background information is needed, such as detailed analyses of the organizations' goals, performance, and leadership. We claim that the here depicted approach can be generally applied, but that the outcomes are highly case specific and need an educated interpretation.

The empirical data for this study were extracted from a 'most likely' multiple-identity case. The organization's hybridity is legally grounded: public and private activities are combined in one not-for-profit organization. This means that not all conclusions of this study might be fully applicable to other multi-identities, but it still offers a handle to perform an analysis of the identities in any organization. Repeating the procedures for other cases could make the conclusions on the dynamics of communicated identities more solid.

We expect that both the ideological identity and the utilitarian identity vary within a certain bandwidth. Some typical identity traits for the one (e.g. 'social') as for the other (e.g. 'business-like') will be universal, given their embeddedness in respective value systems. To what extent each aspect is emphasized (internally or externally) may differ between organizations and even within an organization measured over time.

The comparison between internally perceived identity and projected identity over time can be improved by collecting more quantitative data of the perceived identity. The projected identity is measured by analysing annual reports, for good reasons, but the results can be enriched by taking other communications like an organization's website or social media communication into account as well.

This study is performed in the context of a Western European case. Since the identity question is tied to underlying value systems, and there are differences in work-related values between cultures (Hofstede 1980), our 
conclusions have to be regarded with caution when studying an organization in another part of the world.

At least two avenues for future research lie ahead. First, the research design of this study could be replicated for or adapted to study similar multiple-identity organization cases. This could, for instance, facilitate more structured research on the identities over time, to see to what extent these are indeed as dynamic as demonstrated in this case, and to start understanding cross-organizational differences.

After determining the identity defined by organizational members and the analysis of the projected identity, a valuable next step would be to analyse the perceptions of the organizational multiple identities by the organization's stakeholders.

Funding There is no earmarked funding provided for this paper.

\section{Compliance with Ethical Standards}

Conflict of interest The authors declare that they have no conflict of interest.

Ethical Standard The Executive Board of Sanquin has taken cognizance of this paper and approves publication.

Open Access This article is distributed under the terms of the Creative Commons Attribution 4.0 International License (http://creative commons.org/licenses/by/4.0/), which permits unrestricted use, distribution, and reproduction in any medium, provided you give appropriate credit to the original author(s) and the source, provide a link to the Creative Commons license, and indicate if changes were made.

\section{Appendix A}

General and case-specific traits of ideological and utilitarian identities

\begin{tabular}{ll}
\hline Ideological & Utilitarian \\
\hline Altruism & \\
Human oriented & Process oriented \\
Public & Private \\
Social & Business-like \\
Not for profit & Commercial \\
& Customer oriented \\
Case-bound (Sanquin) & \\
Focus on (well-being of) donors & Donor as a producer of \\
& raw material \\
Patient's health & Patient as a consumer of \\
& medicines \\
& Focus on pharmaceutical \\
& industry
\end{tabular}

Common traits (Sanquin)

Healthcare

\section{Appendix B}

Correlation matrix
Healthcare Patient's Social Commer- Business- Private Customer Human Process Ideological Utilitarian health cial like centred centred centred self-

reflection reflection

\begin{tabular}{|c|c|c|c|c|c|c|c|c|c|c|c|}
\hline Health care & - & & & & & & & & & & \\
\hline Patient's health & .613 & - & & & & & & & & & \\
\hline Social & .569 & .463 & - & & & & & & & & \\
\hline Commercial & .150 & -.035 & .097 & - & & & & & & & \\
\hline Business-like & .337 & .147 & .302 & .476 & - & & & & & & \\
\hline Private & .061 & -.015 & .037 & .517 & .332 & - & & & & & \\
\hline Customer centred & .186 & .049 & .148 & .103 & .223 & .011 & - & & & & \\
\hline Human centred & .273 & .226 & .535 & -.084 & -.020 & -.080 & -.026 & - & & & \\
\hline Process centred & .453 & 309 & .349 & .569 & .556 & .512 & .179 & -.016 & - & & \\
\hline $\begin{array}{l}\text { Ideological self- } \\
\text { reflection }\end{array}$ & .211 & .115 & .329 & .091 & .208 & .013 & .045 & .164 & .131 & - & \\
\hline $\begin{array}{l}\text { Utilitarian self- } \\
\text { reflection }\end{array}$ & .296 & .192 & .315 & .097 & .354 & .106 & .197 & .125 & .225 & .220 & - \\
\hline
\end{tabular}




\section{Appendix C}

Scree plot of eigenvalues

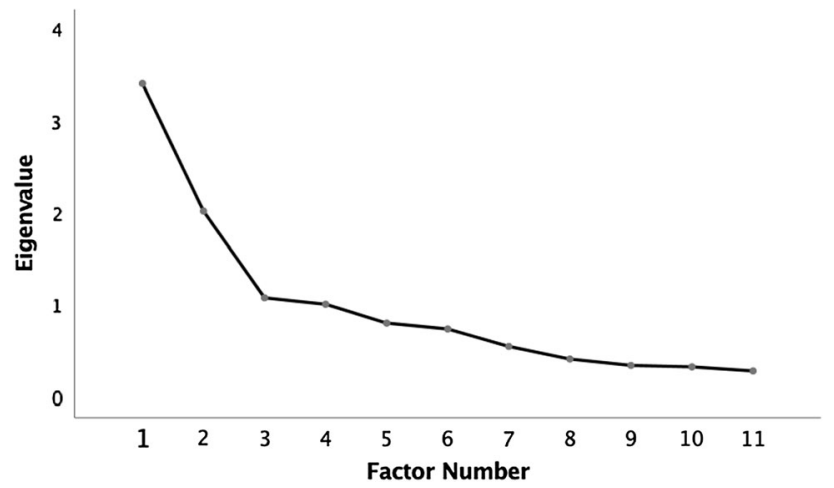

Appendix $C$ This scree plot substantiates the identification of two factors: the ideological (1) and the utilitarian identity (2).

\section{Appendix D}

\section{Characterization of the leadership}

1. The engineer (1998-2011).

This president was called a technocrat by many people within the organization. This is in harmony with his academic background: a $\mathrm{PhD}$ in Technical Studies (Delft University). His management style was 'blue' and cautious. In this manner, he shepherded the organization through many restructurings. His favourite wisdom was that animals survive in the woods more easily than in the prairie.

2. The entrepreneur (2011-2015)

This president is to the present day the one and only Board Member without an academic grade, a self-made man. He has won his spurs in the international world of the pharmaceutical industry. He showed off as an entrepreneur and anti-bureaucrat. He advocated, for instance, that introducing a new rule should imply the abolition of two others.

\section{The diplomate (since 2015)}

This president has been a UN representative and an ambassador to China, among other governmental jobs. One of his first deeds was to reintroduce the blood donor in the mission statement of the organization. People describe him as talented and with a ready tongue.

The interim president of 2014, the caretaker, who consciously refrained from leaving his mark on the organization, has been left out of consideration.

\section{References}

Albert, S., \& Whetten, D. A. (1985). Organizational identity. Research in Organizational Behavior, 7, 263-295.

Anderson, Stuart. (2012). Public, private, neither, both? Publicness theory and the analysis of healthcare organisations. Social Science and Medicine, 74(3), 313-322.

Andersson, C. M., Bjärås, G. E. M., Tillgren, P., \& Östenson, C. (2003). Health promotion activities in annual reports of local governments. European Journal of Public Health, 13(3), 235-239.

Ansell, C., Boin, A., \& Farjoun, M. (2015). Dynamic conservatism: How institutions change to remain the same. In S. K. Matthew (Ed.), Institutions and ideals: Philip Selznick's legacy for organizational studies (pp. 89-119). Bradford: Emerald Group Publishing Limited.

Arnett, D. B., German, S. D., \& Hunt, S. D. (2003). The identity salience model of relationship marketing success: The case of nonprofit marketing. Journal of Marketing, 67(2), 89-105. https://doi.org/10.1509/jmkg.67.2.89.18614.

Ashforth, B. E., Rogers, K. M., Pratt, M. G., \& Pradies, C. (2014). Ambivalence in organizations: A multilevel approach. Organization Science, 25(5), 1453-1478.

Ashforth, B. E., Schinoff, B. S., \& Brickson, S. (2018). My company is friendly, "Mine's a rebel": Anthropomorphism and shifting organizational identity from "What" to "Who. Academy of Management Review. https://doi.org/10.5465/amr.2016.0496.

Battilana, Julie, \& Lee, Matthew. (2014). Advancing research on hybrid organizing-Insights from the study of social enterprises. The Academy of Management Annals, 8(1), 397-441.

Bayle-Cordier, J., Mirvis, P., \& Moingeon, B. (2015). Projecting different identities: A longitudinal study of the "Whipsaw" effects of changing leadership discourse about the triple bottom line. The Journal of Applied Behavioral Science, 51(3), 336-374. https://doi.org/10.1177/0021886314553100.

Bhattacherjee, A. (2012). In University of South Florida. In Scholar Commons, Open Textbook Library (Ed.), Social science research: Principles, methods, and practices. Tampa, FL: Anol Bhattacherjee.

Breton, G. (2009). From folk-tales to shareholder-tales: Semiotics analysis of the annual report. Society and Business Review, 4(3), 187-201.

Bryce, H. J. (2007). The public's trust in nonprofit organizations: The role of relationship marketing and management. California Management Review, 49(4), 112-131. https://doi.org/10.2307/ 41166408.

Carroll, C. E. (2008). Organizational image. In The International encyclopedia of communication (pp. 3464-3468).

Chreim, S. (2005). The continuity-change duality in narrative texts of organizational identity. Journal of Management Studies, 42(3), 567-593. https://doi.org/10.1111/j.1467-6486.2005.00509.x.

Cian, L., \& Cervai, S. (2014). Under the reputation umbrella. Corporate Communications: An International Journal, 19(2), 182-199. https://doi.org/10.1108/CCIJ-10-2011-0055.

Corley, K. G., \& Gioia, D. A. (2004). Identity ambiguity and change in the wake of a corporate spin-off. Administrative Science Quarterly, 49(2), 173-208.

Cornelissen, J., \& Harris, P. (2001). The corporate identity metaphor: Perspectives, problems and prospects. Journal of Marketing Management, 17(1-2), 49-71. https://doi.org/10.1362/ 0267257012571456.

Cuadrado-Ballesteros, B., \& Peña-Miguel, N. (2018). The socioeconomic consequences of privatization: An empirical analysis for Europe. Social Indicators Research, 139(1), 163-183. https:// doi.org/10.1007/s11205-017-1713-2. 
Davies, G., \& Chun, R. (2002). Gaps between the internal and external perceptions of the corporate brand. Corporate Reputation Review, 5(2), 144. https://doi.org/10.1057/palgrave.crr. 1540171.

Desai, P. B. (2017). Values practices and identity sustenance in dualidentity organizations. Journal of Human Values, 23(1), 1-12. https://doi.org/10.1177/0971685816673477.

Eisenhardt, K. M., \& Graebner, M. E. (2007). Theory building from cases: Opportunities and challenges. Academy of Management Journal, 50(1), 25-32.

Fiol, C. M., Pratt, M. G., \& O'Connor, E. J. (2009). Managing intractable identity conflicts. Academy of Management. The Academy of Management Review, 34(1), 32-55.

Foreman, P., \& Whetten, D. A. (2002). Members' identification with multiple-identity organizations. Organization Science, 13(6), 618-635.

Fretwurst, B. (2015). Lotus manual. Reliability and accuracy with SPSS, version 1.0. Retrieved 2018 (unpublished manuscript).

Gioia, D. A., Schultz, M., \& Corley, K. G. (2000). Organizational identity, image, and adaptive instability. Academy of Management. The Academy of Management Review, 25(1), 63-81.

Glynn, M. A. (2000). When cymbals become symbols: Conflict over organizational identity within a symphony orchestra. Organization Science, 11(3), 285-298.

Glynn, M. A., Barr, P. S., \& Dacin, M. T. (2000). Pluralism and the problem of variety. The Academy of Management Review, 25(4), 726-734.

Haniffa, R., \& Hudaib, M. (2007). Exploring the ethical identity of Islamic banks via communication in annual reports. Journal of Business Ethics, 76(1), 97-116.

Heckert, R. (2019). Challenges for a multiple identity organization: A case study of the Dutch blood supply foundation. Corporate Reputation Review, 22(3), 101-119. https://doi.org/10.1057/ s41299-019-00065-1

Hofstede, G. (1980). Culture's consequences: International differences in work-related values. Beverly Hills: Sage.

Jäger, U., \& Schröer, A. (2014). Integrated organizational identity: A definition of hybrid organizations and a research agenda. VOLUNTAS: International Journal of Voluntary and Nonprofit Organizations, 25(5), 1281-1306. https://doi.org/10.1007/ s11266-013-9386-1.

Jones, M. A. (2006). A content analysis of customer satisfaction in annual reports. Journal of Consumer Satisfaction, Dissatisfaction and Complaining Behavior, 19, 59-75.

Kashdan, T. B., \& McKnight, P. E. (2011). Dynamic, contextual approaches to studying personality in the social world. Journal of Personality, 79(6), 1177-1190. https://doi.org/10.1111/j.14676494.2011.00737.x

King, B. G. (2015). Organizational actors, character, and Selznick's theory of organizations. In Institutions and ideals: Philip Selznick's legacy for organizational studies. Research in the Sociology of Organizations (Vol. 44, pp. 149-174). Bradford: Emerald Group Publishing Limited. https://doi.org/10.1108/ s0733-558x20150000044007.
Kotler, P. (1979). Strategies for introducing marketing into nonprofit organizations. Journal of Marketing, 43(1), 37-44. https://doi. org/10.2307/1250756.

Lee, T. (1994). Changing form of the corporate report. The Accounting Historians Journal, 21(1), 215.

O'Brien, D. (2017). Dynamic continuity has been our way of looking at life from the very beginning. The Focus, XII(2), 6-15.

Osborn, R. N., \& Ashforth, B. E. (1990). Investigating the challenges to senior leadership in complex, high-risk technologies. The Leadership Quarterly, 1(3), 147-163. https://doi.org/10.1016/ 1048-9843(90)90017-C.

Pratt, M. G., \& Foreman, P. O. (2000). Classifying managerial responses to multiple organizational identities. The Academy of Management Review, 25(1), 18-42.

Ramarajan, L. (2014). Past, present and future research on multiple identities: Towards an intrapersonal network approach. The Academy of Management Annals, 8(1), 1-88. https://doi.org/10. 1080/19416520.2014.912379.

Ries, A., \& Trout, J. (Eds.). (1993). The 22 immutable laws of marketing. Violate them at your own risk!. New York: Harper Business.

Rutherford, B. A. (2005). Genre analysis of corporate annual report narratives: A corpus linguistics-based approach. The Journal of Business Communication, 42(4), 349-378.

Schultz, M., Hatch, M. J., \& Holten Larsen, M. (2000). The expressive organization. Linking identity, reputation, and the corporate brand. Oxford: Oxford University Press.

Schwartz, M., Dunfee, T., \& Kline, M. (2005). Tone at the top: An ethics code for directors? Journal of Business Ethics, 58(1), 79-100. https://doi.org/10.1007/s10551-005-1390-y.

Sillince, J. A., \& Brown, A. D. (2009). Multiple organizational identities and legitimacy: The rhetoric of police websites. Human Relations, 62(12), 1829.

Stevens, J. (1992). Applied multivariate statistics for the social sciences (2nd ed.). Hillsdale, NJ: Lawrence Erlbaum.

Tuškej, U., \& Podnar, K. (2018). Consumers' identification with corporate brands: Brand prestige, anthropomorphism and engagement in social media. Journal of Product \& Brand Management, 27(1), 3-17. https://doi.org/10.1108/JPBM-052016-1199.

Van Damme, E. E. C. (2004). Pragmatic privatization: The Netherlands 1982-2002. TILEC Discussion Paper (Vol. 2004-007). Tilburg: TILEC.

Van Riel, C. B. M. (2012). The alignment factor: Leveraging the power of total stakeholder support. London: Routledge.

Veuger, J. (2018). Derde evaluatie Wet inzake Bloedvoorziening. Invited Talk at ZonMw. Netherlands: Hanze University of Apllied Sciences.

Zafar, A. (2016). How organizations manage the tensions of hybrid identity? Academy of Management Proceedings, 2016(1), 13732.

Publisher's Note Springer Nature remains neutral with regard to jurisdictional claims in published maps and institutional affiliations. 